\title{
Can Pain or Hyperalgesia Be a Classically Conditioned Response in Humans?
}

Citation for published version (APA):

Madden, V. J., Harvie, D. S., Parker, R., Jensen, K. B., Vlaeyen, J. W. S., Moseley, G. L., \& Stanton, T. R. (2016). Can Pain or Hyperalgesia Be a Classically Conditioned Response in Humans? A Systematic Review and Meta-Analysis. Pain Medicine, 17(6), 1094-1111. https://doi.org/10.1093/pm/pnv044

Document status and date:

Published: 01/06/2016

DOI:

10.1093/pm/pnv044

Document Version:

Publisher's PDF, also known as Version of record

\section{Please check the document version of this publication:}

- A submitted manuscript is the version of the article upon submission and before peer-review. There can be important differences between the submitted version and the official published version of record.

People interested in the research are advised to contact the author for the final version of the publication, or visit the DOI to the publisher's website.

- The final author version and the galley proof are versions of the publication after peer review.

- The final published version features the final layout of the paper including the volume, issue and page numbers.

Link to publication

\footnotetext{
General rights rights.

- You may freely distribute the URL identifying the publication in the public portal. please follow below link for the End User Agreement:

www.umlib.nl/taverne-license

Take down policy

If you believe that this document breaches copyright please contact us at:

repository@maastrichtuniversity.nl

providing details and we will investigate your claim.
}

Copyright and moral rights for the publications made accessible in the public portal are retained by the authors and/or other copyright owners and it is a condition of accessing publications that users recognise and abide by the legal requirements associated with these

- Users may download and print one copy of any publication from the public portal for the purpose of private study or research.

- You may not further distribute the material or use it for any profit-making activity or commercial gain

If the publication is distributed under the terms of Article $25 \mathrm{fa}$ of the Dutch Copyright Act, indicated by the "Taverne" license above, 


\section{Review Article}

\section{Can Pain or Hyperalgesia Be a Classically Conditioned Response in Humans? A Systematic Review and Meta-Analysis}

Victoria J. Madden, BSc, ${ }^{*}$ Daniel S. Harvie, PhD, ${ }^{*, \dagger}$ Romy Parker, PhD, ${ }^{\ddagger}$ Karin B. Jensen, PhD,\$ Johan W.S. Vlaeyen, PhD,,$\|$ G. Lorimer Moseley, $\mathrm{PhD}^{*, \|}$ and Tasha R. Stanton, PhD*,\||

*Sansom Institute for Health Research, University of South Australia, Adelaide, Australia; ${ }^{\dagger}$ CONROD, Menzies Health Institute Queensland, Griffith University, Australia; ${ }^{\mp}$ Department of Health and Rehabilitation Sciences, University of Cape Town, Cape Town, South Africa; §Department of Clinical Neuroscience, Karolinska Institute, Stockholm, Sweden; "Research Group Health Psychology, KU Leuven, Leuven, Belgium; "Department Clinical Psychological Science, Maastricht University, Maastricht, The Netherlands; "INeuroscience Research Australia, Sydney, Australia

Correspondence to: G. Lorimer Moseley, PhD, Body in Mind Research Group, GPO Box 2471, University of South Australia, Adelaide 5001, Australia. Tel: 618 8302 1416; Fax: 618 83022853;

E-mail: lorimer.moseley@gmail.com.

Funding sources: Victoria J. Madden is supported by the Oppenheimer Memorial Trust (South Africa). Johan W.S. Vlaeyen is supported by the Odysseus Grant, "The Psychology of Pain and Disability Research Program" funded by the Research Foundation Flanders (FWO-Vlaanderen), Belgium. G. Lorimer Moseley is supported by an Australian National Health \& Medical Research Council Principal Research Fellowship (ID 1061279). Tasha R. Stanton is supported by an Australian National Health \& Medical Research Council Early Career Fellowship (ID 1054041). Victoria J. Madden received scholarships from the Pain, Mind and Movement SIG of the IASP and from the South African Society of Physiotherapy to attend that congress. This project was supported by an Australian National Health \& Medical Research Council Project grant to G. Lorimer Moseley (ID 1047317).
Conflicts of interest: All authors declare no conflicts of interest relevant to this work.

Disclosure: Victoria J. Madden, Daniel S. Harvie, Johan W.S. Vlaeyen, G. Lorimer Moseley, and Tasha R. Stanton conceived and designed the study. Victoria J. Madden, Daniel S. Harvie, Romy Parker, Karin B. Jensen, and Johan W.S. Vlaeyen collected and analyzed data. All authors were involved in data interpretation and critical revision of the manuscript, and approved the final version.

\begin{abstract}
Background. Clinical scenarios of repeated pain usually involve both nociceptive and non-nociceptive input. It is likely that associations between these stimuli are learned over time. Such learning may underlie subsequent amplification of pain, or evocation of pain in the absence of nociception.
\end{abstract}

Methods. We undertook a systematic review and meta-analysis to evaluate the evidence that allodynia or hyperalgesia can be a classically conditioned response. A sensitive search of the literature covered Medline, Embase, CINAHL, AMED, PubMed, Scopus, PsycArticles, PsycINFO, Cochrane Library, and Web of Science. Additional studies were identified by contacting experts and searching published reviews. Two reviewers independently assessed studies for inclusion, evaluated risk of bias, and extracted data. Studies were included if they aimed to elicit or amplify pain using a classical conditioning procedure in healthy, adult humans. Studies were excluded if they did not distinguish between classical conditioning and explicit verbal suggestion as learning sources, or did not use experiential learning.

Results. Thirteen studies, with varying risk of bias, were included. Ten studies evaluated classically conditioned hyperalgesia: nine found hyperalgesia; one did not. Pooled effects ( $n=8$ with full data) showed a significant pain increase after conditioning (mean difference of 7.40 [95\% Cl: $4.00-10.80]$ on a $0-100$ pain scale). Three studies evaluated conditioned allodynia and found conflicting results. 
Conclusion. The existing literature suggests that classical conditioning can amplify pain. No conclusions can be drawn about whether or not classical conditioning can elicit pain. Rigorous experimental conditioning studies with nociceptive unconditioned stimuli are needed to fill this gap in knowledge.

\section{Key Words. Pain, Classical Conditioning; Pavlovian Conditioning; Associative Learning; Hyperalgesia; Allodynia}

\section{Introduction}

Pain is most often associated with nociceptive input, yet it is distinct from that input. Current concepts of pain emphasize that it is evoked by the inference that bodily tissues are in danger [1,2], and that this inference depends on an evaluation of sensory and non-sensory information on the background of prior knowledge [3]. Importantly, the sensory information may or may not include nociceptive input. With this view, nociception is neither sufficient nor necessary for pain [for full review, see 4].

In clinical scenarios of pain, nociceptive input never occurs in isolation, but is preceded or accompanied by non-nociceptive input. For example, in a case of back pain, nociception at a certain point in a forward bending movement is unavoidably paired with information from proprioceptors as well as with visual information confirming the direction and magnitude of movement. This presents a situation where associations between nociceptive and non-nociceptive stimuli are likely to be learned. This form of associative learning follows the principles first proposed by Ivan Pavlov during the 19th century [5]. Indeed, the idea that Pavlovian conditioning could evoke pain has previously been mooted [for brief review, see 6], but experimental investigation of the idea has been limited [7].

Pavlov proposed that an initially neutral stimulus may come to evoke a response because it has repeatedly been paired with a stimulus that automatically elicits the response. The terminology is such that the neutral stimulus is called the conditioned stimulus (CS), the response is called the conditioned response (CR), and the initial stimulus, which automatically elicits an unconditioned response (UCR), is called the unconditioned stimulus (UCS). However, a more modern view of classical conditioning asserts that learning is shaped not only by the pairing of the CS and the UCS, but by the informational value that the CS contains about the upcoming UCS [8].

A large body of literature already suggests that the effects of classical conditioning may play a notable role in chronic pain conditions, specifically in the development of chronic pain-related fear and disability [9]: classical conditioning is thought to be a learning process underlying the fear of pain that drives progressive avoidance of activity [10]. Critically, that research considers pain (and its mental representation) to be the UCS. However, nociceptive input can also be considered a UCS and pain the conditioned response elicited by non-nociceptive input associated with the nociceptive UCS (Figure 1). For example, Williams and Rhudy [11] conducted an experiment in which healthy participants were taught to associate certain images (CS+) with aversive electrocutaneous stimulation (UCS), and other images (CS-) with no aversive stimulation. They then compared pain thresholds, valence, and arousal as measured while participants viewed the CS + images to those measured while they viewed the CS- images. They expected that classical conditioning would lead to fear, and that that fear would cause a drop in pain threshold. However, an alternative possibility is that such a drop in pain threshold might not be reliant on fear, but could be the direct effect of viewing the $\mathrm{CS}+$ image after the classical conditioning procedure. In other words, it is plausible to suggest that pain might become a classically conditioned response, one that is driven not by nociception, but by non-nociceptive input that has been previously associated with nociception.

Although the idea that fear of pain can be classically conditioned is well studied and largely supported; this idea that the experience of pain itself can be a classically conditioned response has received far less attention [7]. That may be because the distinction between pain and nociception, although highlighted almost 30 years ago [12], has only recently become well accepted. That the experience of pain is an output-rather than a sensory input-urges us to reconsider the possible role of classical conditioning in the perception of pain.

We aimed to evaluate whether classical conditioning alone can be used to elicit pain (conditioned allodynia) or amplify pain (conditioned hyperalgesia) in healthy humans. We therefore conducted a systematic and meta-analytical review to synthesize the experimental evidence that allodynia or hyperalgesia can be classically conditioned in healthy, adult humans.

\section{Methods}

\section{Data Sources}

This systematic review was executed using an a priori protocol (Supplementary file 1) according to the recommendations of the Preferred Reporting Items for Systematic Reviews and Meta-Analyses (PRISMA) statement [13] and Cochrane guidelines [14]. A sensitive search strategy was designed with advice from an expert librarian, and included the Cochrane Library, PubMed, MEDLINE (via OvidSP), Embase (via OvidSP), AMED (via Ovid SP), CINAHL (via EBSCOhost), Web of Science (via Web of Knowledge), Scopus, PsycINFO (via EBSCOhost), and PsycArticles (via EBSCOhost) from date of inception to February 3, 2015. The search was not restricted by article language, but was restricted to humans where possible. Databases were 


\section{Madden et al.}

(a)

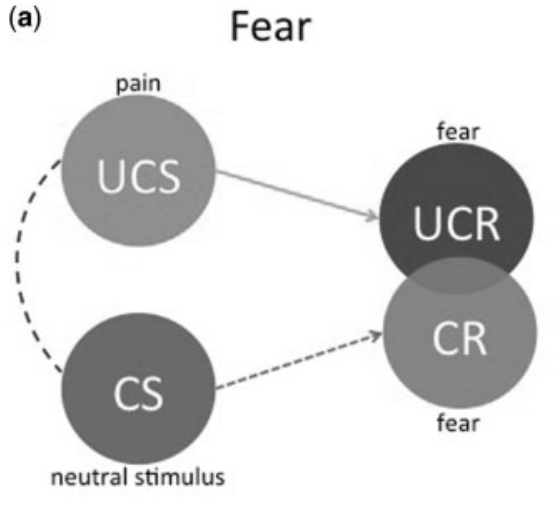

(b)

Pain

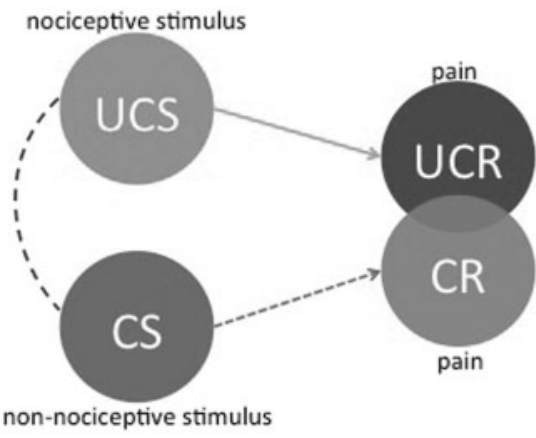

Figure 1 Graphical representations of processes involved in classical conditioning of fear (a) and pain (b). UCS = unconditioned stimulus; $C S=$ conditioned stimulus; $\quad \mathrm{UCR}=$ unconditioned response; $\mathrm{CR}=$ conditioned response. The UCS consistently elicits the UCR (shown by the solid line). Pairing of UCS and CS (shown by the stippled arc) renders the CS capable of eliciting the $\mathrm{CR}$ (shown by the stippled straight line). The UCR and CR usually share certain elements. searched using key search terms related to classical conditioning and pain, and, where they were available, subject headings specific to each database. Full search details are provided in Supplementary file 2. Review articles in the field of classical conditioning, pain, and placebo/nocebo effects (an area known to have explored modulation of pain by classical conditioning) were hand-searched for relevant citations. The final list of included articles was sent to recognized authors in the field to screen for any missed studies, including any that might not have reached publication.

\section{Study Selection}

Studies were included if they tested for a classical conditioning effect on pain in healthy, pain-free humans over 18 years old, and hypothesized, expected, or were designed so as to detect the onset of pain (allodynia), or an increase in pain (hyperalgesia) as the conditioned response, using a quantitative measure of pain intensity, pain threshold, or pain tolerance.

Both simple and differential conditioning designs were eligible for inclusion. Within this context, simple conditioning designs used one CS and measured the response to that stimulus before and after pairing with the UCS; differential designs used a contrast comparison between two CSs, typically pairing one CS (denoted $\mathrm{CS}+$ ) with the UCS, and presenting the other CS (CS-) unpaired.

Studies that used observational learning were excluded. Studies were also excluded if they used explicit verbal suggestion such that participants might anticipate a change in pain a priori.
No restriction was placed on the nature of the conditioned or unconditioned stimuli used (e.g., electrical, radiant, or contact heat, etc.) or on the stated primary aim of the study: if studies met the above criteria, they were included, regardless of whether the study's primary aim was to evaluate the classical conditioning of allodynia or of hyperalgesia. The terms 'allodynia' and 'hyperalgesia' are used in this article to aid readability, but studies were not required to have used the same terms to be eligible for inclusion in this review. We considered classical conditioning of allodynia to occur when a stimulus that is non-painful at baseline becomes painful after the conditioning procedure, or when conditioning induces a change in pain threshold. We considered classical conditioning of hyperalgesia to occur when a stimulus that is painful at baseline becomes more painful after the conditioning procedure.

During study screening, disagreements about inclusions led to clarification and extension of the inclusion criterion related to the procedural details in both simple and differential designs: CSs had to be neutral with respect to pain prior to pairing. The disagreement statistic reported in the Results section reflects this decision.

\section{Study Screening Process}

Records identified in the searches were exported to EndNote (Version X7, Thomson Reuters, New York, NY, USA) and duplicates were removed. The remaining titles and abstracts were screened by two independent reviewers (Victoria J. Madden and Romy Parker) to exclude articles that were clearly irrelevant. Full texts were obtained for all potentially relevant articles, and two reviewers (Victoria J. Madden and Daniel S. Harvie) independently assessed the full articles for eligibility, using a customized and previously piloted form 


\section{Classically Conditioned Pain and Hyperalgesia in Humans}

(Supplementary file 3). Disagreements were resolved by discussion or consultation with a third, independent reviewer.

\section{Bias Assessment}

A risk of bias tool was custom-formulated using items from the Cochrane Collaboration's risk of bias tool [14] and considerations relevant to experimental study designs and classical conditioning procedures (Supplementary file 4). Points of particular emphasis were established a priori, including sample size, the allocation of participants to groups, blinding of participants, calibration of stimulus to individual participants (where relevant), and the use of manipulation checks (where relevant). Studies were rated according to the risk that their results might be biased for the purposes of answering the question of this review. Two independent reviewers (Victoria J. Madden and Daniel S. Harvie) used this tool to assess risk of bias for each included study. Disagreements were resolved by discussion. The tool produced ratings of six potential sources of bias: selection bias; blinding procedures; measurement bias; reporting bias; details of the conditioning procedure; concerns relating to statistical methods, study size and other confounders; and reporting bias. Small sample sizes have been shown to overestimate the effect of an intervention [15-17]. While no recommendations for sample size currently exist for within-subject designs, a conservative estimate was used to judge risk of bias in these studies. Specifically, studies recruiting fewer than 50 participants in total were considered to have a high risk of bias (a conservative estimate because subjects act as their own control, reducing variability). If an a priori sample size calculation was reported and the target met, we considered this to be a low risk of bias, regardless of participant number.

\section{Data Extraction}

Two independent reviewers (Victoria J. Madden and Daniel S. Harvie) used a customized, piloted template to extract data from the studies (Supplementary file 5). All extracted data were compared between reviewers for accuracy. Extracted data included participant demographic characteristics (age, gender, number, inclusion and exclusion criteria), conditioning procedure (overall design, natures of CSs, UCS, and test stimuli), measurement tools, pain results (type of conditioned response [mean and standard deviation from each group], effect size), data on additional outcomes (skin conductance responses, startle responses), analytical approaches, and the manipulation checks that were performed. Additional information was sought from study authors via email when required.

\section{Data Analysis and Meta-Analytical Approach}

If a study assessed for a change in response to a stimulus that was known to be painful at baseline (prior to the classical conditioning procedure), it was considered to be investigating classically conditioned hyperalgesia. If a study assessed for a change in pain threshold-either by traditional threshold measures or by measuring the response to a stimulus that was known to be nonpainful at baseline, or painful only in an established proportion of trials - it was considered to be investigating classically conditioned allodynia.

An a priori decision was made to pool data if more than one eligible study used similar conditioning paradigms and similar pain outcomes. For the studies that were eligible for meta-analysis, authors were contacted and asked to provide their raw data.

Pain scores for CS + and CS- were averaged for each individual participant, and then re-scaled to a 0-100 scale on which 0 represented "no pain" and 100 represented "maximal pain level". For differential designs, we calculated a difference between means (mean pain to $\mathrm{CS}+$ minus mean pain to CS-) for each individual. We then calculated the mean, standard deviation, and standard error $\left(\mathrm{SE}(\mathrm{MD})=\mathrm{SD}_{\text {diff }} / \sqrt{ } \mathrm{n}\right)$ of that difference between means at a sample level. This is in line with The Cochrane Collaboration's suggestions for withinsubject data (i.e., cross-over studies).

Mean and SE data were entered using the generic inverse function of Review Manager software (Version 5.2, Copenhagen: The Nordic Cochrane Centre, The Cochrane Collaboration, 2012) and pooled using a random effects model. Heterogeneity of pooled studies was assessed using the $\mathrm{X}^{2}$ test and $\mathrm{I}^{2}$ statistic. Heterogeneity was considered statistically significant when $X^{2} P<0.10$ and substantial when $\mathrm{I}^{2}$ exceeded $60 \%$ [14]. Lastly, we performed a subgroup analysis based on whether the protocol employed somatosensory CSs or non-somatosensory CSs. We defined somatosensory stimuli as those that are transmitted primarily via the somatosensory pathways. This includes nociceptive, tactile, and proprioceptive information. Visual, auditory, gustatory (taste), olfactory (smell), and vestibular (balance) stimuli were considered nonsomatosensory stimuli.

\section{Exploratory Analysis}

An exploratory analysis was conducted on data from hyperalgesia studies that used differential designs. It is not unreasonable to suggest that the reported difference in pain intensity between the stimuli paired with CS + versus the stimuli paired with the CS- during an acquisition phase could influence the equivalent difference during a subsequent test phase. We assessed this by correlating the mean difference in reported painfulness during the acquisition phase with the mean difference in reported painfulness during the test phase.

\section{Results}

Of the 4,801 records identified by the search strategy, 4,787 did not meet the initial eligibility criteria, leaving 14 


\section{Madden et al.}

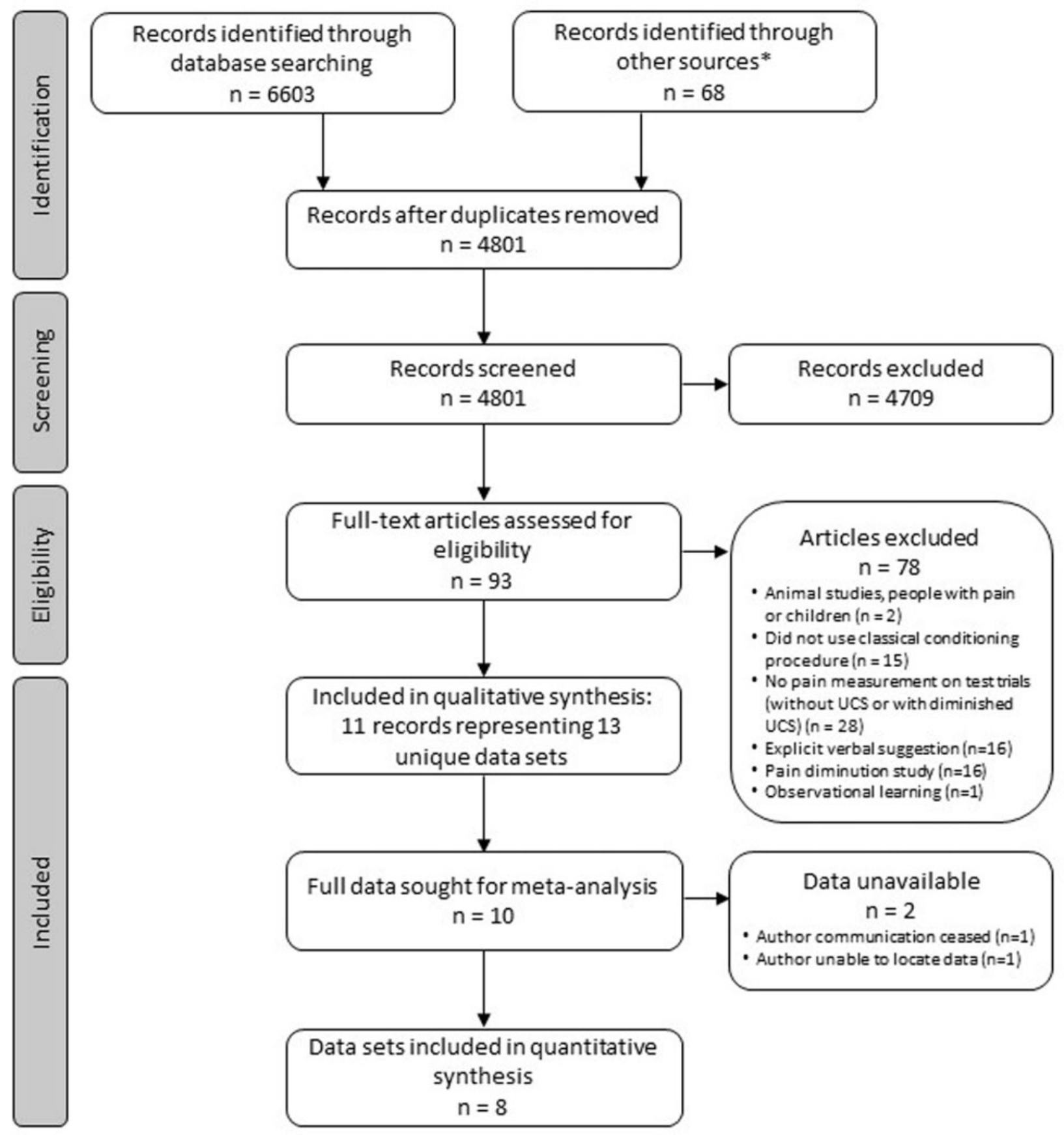

Figure 2 PRISMA flow chart showing selection process including reasons for exclusion. *Sources: hand-searching of reference lists $(n=43)$ and recommendations by experts $(n=25)$. Of these 68 records, 13 were duplicates, 41 were excluded on initial screening, seven were excluded on full-text assessment, and seven were included in the final 14 records.

potentially eligible records (Figure 2). Some disagreement about eligibility (Kappa statistic $=0.55$ ) and the retrieval of one article with an unusual design [18] prompted extensive discussion about inclusion criteria. Clarification of one inclusion criterion (related to the details of the classical conditioning procedure) via discussion with the third reviewer (Johan W.S. Vlaeyen) led to the exclusion of three [18-20] of the records, leaving a final number of 11. One article [21] and one thesis [22] reported on two studies each, so the total number of eligible data sets was 13: seven published articles (reporting on a total of seven studies), one 


\section{Classically Conditioned Pain and Hyperalgesia in Humans}

conference abstract, three thesis studies, and two unpublished experiments. We successfully contacted all the authors and allowed 3 months for responses. Full raw data sets were obtained for eight studies. Characteristics of the included studies are listed in Tables 1 and 2. Table 3 lists the outcomes used by each study. Where more than one outcome measure was used for pain or a closely related construct, the final column of Table 3 states whether or not the additional outcome corroborated the primary pain results.

Seven of the 13 included studies evaluated this review's question as a primary aim. Eleven studies used a differential conditioning paradigm and two used a simple conditioning paradigm. All studies but one used participants' reports of pain intensity as an outcome; the remaining study used a behavioral outcome that effectively indicated participants' self-reported pain threshold: participants were instructed to withdraw as soon as the test stimulus became painful, and the outcome measure was withdrawal latency [11]. Twelve studies used a painful UCS; one used a non-painful UCS [11]. Four studies used a somatosensory CS; nine used a nonsomatosensory CS. Two studies also reported on groups with chronic pain [23,24], but the current review used only the healthy participant data from these studies.

\section{Risk of Bias}

Risk of bias assessment yielded mixed results (Table 4). The four unpublished studies [25-28] could not be assessed for risk of bias and therefore have been assigned an unclear risk of bias. All the peer-reviewed, published studies had high risk of bias for the domains of blinding (none reported having assessed participant blinding) and for the "statistical methods, study size, and confounding" category, but low risk of measurement bias - with the exception of the study by Williams and Rhudy [11], which scored high risk of measurement bias. Eight of nine studies had low risk of reporting bias, and bias related to the conditioning procedure. Selection bias findings were mixed.

\section{Classical Conditioning of Hyperalgesia $(N=10)$}

Ten studies, with 255 participants (see note on Table 1), investigated hyperalgesia. Eight studies demonstrated hyperalgesia [21,23,26,27,29,30] and two [22 Exp 2, 25] did not. Only one study [25] used a simple conditioning design. The remaining nine studies with differential conditioning designs used a reduced intensity of the UCS as a test stimulus during the test phase. Two of the studies $[25,27]$ were not described in full (one conference abstract; one pilot study, mentioned in a PhD thesis), and we are unable to describe their designs in detail. Of the remaining eight studies, seven [21,22 Exp 2 , 26,28-30] investigated hyperalgesia as a primary response and one study [23] assessed hyperalgesia as a secondary response (by evaluating the effect of fear on pain).

\section{Assessing Hyperalgesia as a Primary Response}

Of the seven studies, five [21,28-30] used nonsomatosensory CSs (visual stimuli with no emotional valence) and demonstrated hyperalgesia to stimuli paired with the CS + compared with those paired with the CS- after the classical conditioning procedure. The other two studies [22 Exp 2, 26] used somatosensory CSs. One [26] demonstrated classically conditioned hyperalgesia, and the other [22 Exp 2] did not.

Harvie et al. [26] used a vibrotactile CS and a transcutaneous electrical stimulus as UCS, and also applied trace, delay, and simultaneous timing to explore the effects of stimulus timing on acquisition of hyperalgesia. Their results demonstrated classically conditioned hyperalgesia, regardless of stimulus timing. Bräscher's Experiment 2 paired thermal stimuli of two different temperatures (counterbalanced as CS + and CS-) with moderately and mildly painful heat stimuli. These CSs and UCSs were contact heat from the same probe. The data show a classically conditioned hyperalgesic effect in 11 of 22 participants [22], but overall analysis of the data shows no statistically significant difference between CS + and CS- painfulness after conditioning. Arntz [25] used a mildly painful electrical stimulus as a CS, and a painful muscular contraction as a UCS. This was a pilot experiment, reported in a doctoral dissertation, and also found no hyperalgesic effect after conditioning.

\section{Assessing Hyperalgesia as a Secondary Response}

One study [23] assessed hyperalgesia as a secondary response by evaluating the effect of fear, which was expected to modulate the painfulness of a thermal test stimulus. The CSs were non-somatosensory-neutral visual stimuli (square/triangular shapes)-and the UCS was a thermal stimulus. That study's results demonstrated conditioned fear and conditioned hyperalgesia.

\section{Meta-Analysis of Hyperalgesia Studies}

Data were obtained from all eight full-text studies for pooling (see Figure 2 for process). Pooling (Figure 3) yielded an estimated pain increase of 7.40 points on a 0-100 scale of pain intensity (95\% Cl: 4.00-10.80), suggesting that hyperalgesia can be induced using classical conditioning. Heterogeneity between these pooled studies was high $\left(X^{2}=71.61, \mathrm{df}=7, P<0.00001 ; I^{2}=90 \%\right)$, likely due to small sample sizes, the wide variation in type of CS, conditioning procedure, and study designs. Of the two studies for which neither full-text descriptions nor raw data could be obtained, one did and one did not find evidence for classical conditioning of hyperalgesia. Those studies could not be assessed for risk of bias (Table 4). 


\section{Madden et al.}

Table 1 Details of included studies: (A) Studies investigating classically conditioned hyperalgesia; (B) Studies investigating classically conditioned pain

Study design

\begin{tabular}{|c|c|c|c|c|c|c|}
\hline Study & $\begin{array}{l}\text { Primary } \\
\text { question } \\
\text { of study } \\
\text { related } \\
\text { to: }\end{array}$ & $\begin{array}{l}\text { Pain-related } \\
\text { outcome }\end{array}$ & $\begin{array}{l}\text { Pain } \\
\text { measure }\end{array}$ & $\begin{array}{l}\text { Analytical } \\
\text { approach to } \\
\text { comparison* }\end{array}$ & $\begin{array}{l}\text { Number } \\
\text { of } \\
\text { participants }\end{array}$ & Design $^{\dagger}$ \\
\hline \multicolumn{7}{|c|}{ (A) Studies investigating classically conditioned hyperalgesia } \\
\hline Arntz [19] & Pain & Intensity & VAS $0-100$ & control & $12^{\ddagger}$ & $\begin{array}{l}\text { Simple trace (unknown } \\
\text { time) }\end{array}$ \\
\hline Aslaksen et al. [27] & Pain & Intensity & $\begin{array}{l}\text { VAS; scale } \\
\text { not stated. }\end{array}$ & control & $\sim 32^{\S}$ & Simple delay \\
\hline $\begin{array}{l}\text { Bräscher thesis } \\
\text { Experiment } 2 \text { [22] }\end{array}$ & Pain & Intensity & VAS $40-100^{\pi}$ & $\mathrm{CS}+/-$ & $22^{\|}$ & $\begin{array}{l}\text { Differential trace } \\
\quad \text { (unknown time) }\end{array}$ \\
\hline Harvie et al. [26] & Pain & Intensity & $\begin{array}{l}\text { VAS-intensity } \\
\text { VAS-unpleas- } \\
\text { antness; } \\
\text { each 0-150 } \\
\text { mm }\end{array}$ & $\mathrm{CS}+/-$ & 54 & $\begin{array}{l}\text { Differential simultaneous/ } \\
\text { delay }{ }^{\|}\end{array}$ \\
\hline Jenewein et al. [23] & Fear & Intensity & $\begin{array}{l}\text { VAS 0-100 } \\
\text { mm }\end{array}$ & $\mathrm{CS}+/-$ & 14 & Differential trace $(0 \mathrm{sec})$ \\
\hline $\begin{array}{l}\text { Jensen et al. } 2012 \\
\text { Experiment } 1 \text { [21] }\end{array}$ & Pain & Intensity & NRS 0-100 & $\mathrm{CS}+/-$ & 20 & Differential trace (0 sec) \\
\hline $\begin{array}{l}\text { Jensen et al. } 2012 \\
\text { Experiment } 2 \text { [21] }\end{array}$ & Pain & Intensity & NRS 0-100 & $\mathrm{CS}+/-$ & 20 & Differential trace $(0 \mathrm{sec})$ \\
\hline $\begin{array}{l}\text { Jensen et al. } 2014 \\
\text { [30] }\end{array}$ & Pain & Intensity & NRS 0-20 & $\mathrm{CS}+/-$ & 24 & Differential trace $(0 \mathrm{sec})$ \\
\hline $\begin{array}{l}\text { Jensen et al. } 2015 \\
\text { [28] }\end{array}$ & Pain & Intensity & NRS 0-100 & $\mathrm{CS}+/-$ & 49 & Differential trace (0 sec) \\
\hline $\begin{array}{l}\text { Ploghaus et al. } 2001 \\
\text { [29] }\end{array}$ & Anxiety & Intensity & NRS $1-5$ & $\mathrm{CS}+/-$ & 8 & Differential delay \\
\hline \multicolumn{7}{|c|}{ (B) Studies investigating classically conditioned pain } \\
\hline Klinger et al. [24] & $\begin{array}{l}\text { Muscular } \\
\text { response }\end{array}$ & Intensity & NRS 0-10 & $\mathrm{CS}+/-$ & 18 & Differential delay \\
\hline $\begin{array}{l}\text { Bräscher thesis } \\
\text { Experiment } 1 \text { [22] }\end{array}$ & Pain & Intensity & VAS $40-100^{\pi}$ & $\mathrm{CS}+/-$ & $21^{\|}$ & Differential trace (0 sec) \\
\hline $\begin{array}{l}\text { Williams and Rhudy } \\
\text { [11] }\end{array}$ & Fear & Threshold & $\begin{array}{l}\text { Withdrawal } \\
\text { latency time }\end{array}$ & $\mathrm{CS}+/-$ & $\sim 21^{\S}$ & Differential trace $(0 \mathrm{sec})$ \\
\hline
\end{tabular}

${ }^{*}$ Refers to whether the study design compared outcomes between an experimental and a control group (control), between $\mathrm{CS}+$ and CS- within the same participants $(\mathrm{CS}+/-)$, or between ratings of $\mathrm{CS}+$ within the same participants but between different phases (phase). UCS = unconditioned stimulus; VAS = visual analog scale; NRS = numerical rating scale; CS $=$ conditioned stimulus.

${ }^{\dagger}$ The time period between the offset of CS and onset of UCS is specified for each case of trace timing. Designs in which the CS offset coincided with UCS onset are defined here as trace timing $(0 \mathrm{sec})$ because there is no temporal overlap between CS and UCS.

¥This study used a between-group design (total $\mathrm{N}=33$ ); only the experimental group is counted here.

§These studies used between-group designs (total $\mathrm{N}=64$ and $\mathrm{N}=42$, respectively) and did not specify the number of participants in each of the two groups. We have assumed equal group sizes to yield these figures for $\mathrm{N}$.

"This VAS had anchors of: $0=$ warm; $40=$ just painful; $100=$ very strong pain. The pain section of the scale is represented here. "These studies used a within-subject design (total $\mathrm{N}=22$ and $\mathrm{N}=21$, respectively) and found pain-related classically conditioned effects in subgroups ( $\mathrm{N}=11$ and $\mathrm{N}=13$, respectively) of participants.

IIThis study used three different timings, one of which was designed and demonstrated to be perceptually simultaneous although, technically, it was a $20 \mathrm{~ms}$ delay design. 


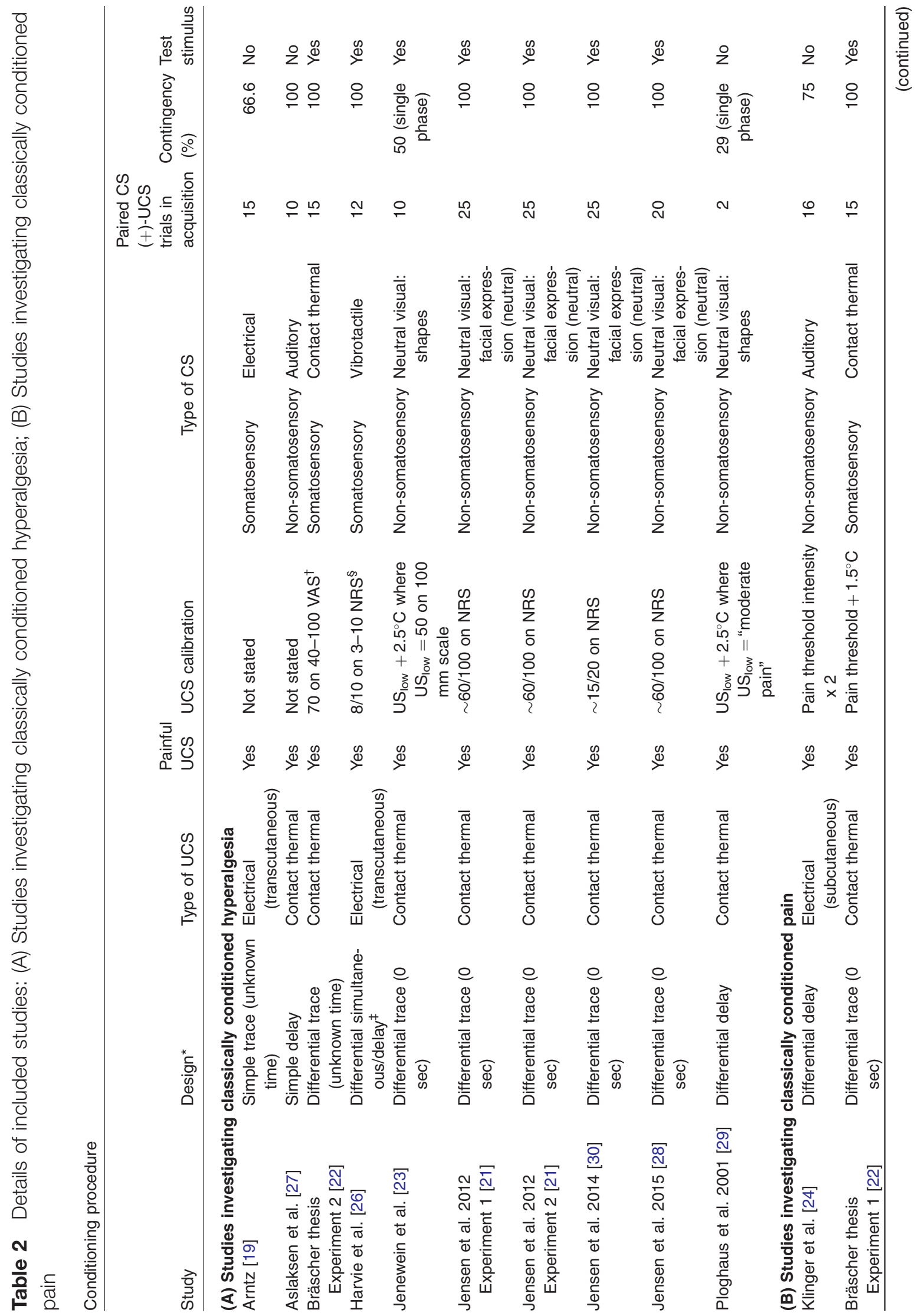




\section{Madden et al.}

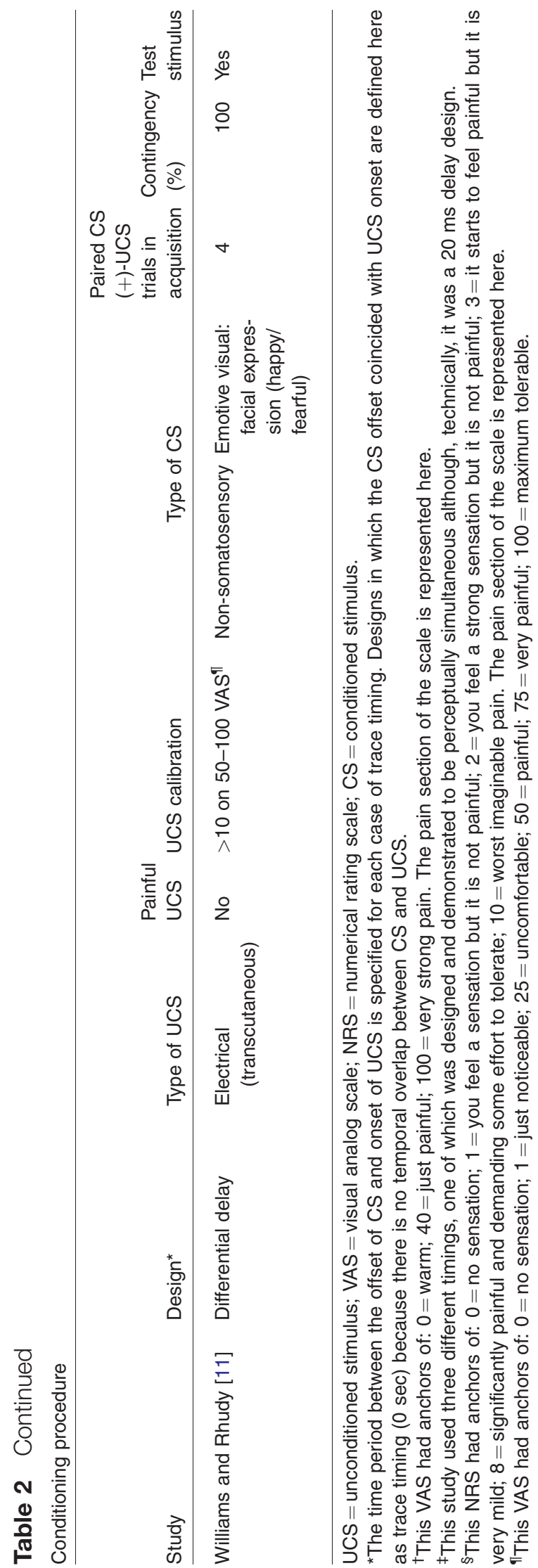

Subgroup analysis by type of CS (Figure 4) showed a pooled effect estimate (pain increase on a 0-100 scale of pain intensity) of 1.62 [95\% Cl: -0.05 to 3.30] for studies using a somatosensory CS and 9.71 [95\% Cl: 6.92-12.50] for studies using a non-somatosensory CS.

\section{Exploratory Analysis of Hyperalgesia Studies}

Data for this analysis were available from five studies [21,26,28,30], representing 163 participants. There was a significant relationship between the mean difference in reported painfulness during acquisition phase and the mean difference in reported painfulness during test phase, Spearman's rho $=0.237, P<0.01$.

\section{Classical Conditioning of Allodynia $(\mathrm{N}=3)$}

Three studies [11,22 Exp 1, 24] evaluated classical conditioning of allodynia. One found that allodynia can be classically conditioned, and two did not. Two studies evaluated allodynia as a secondary response $[11,24]$.

The primary question of Bräscher's Experiment 1 [22] matched that of this review. That study used an acquisition procedure in which CS + and CS- (32 and $36^{\circ} \mathrm{C}$ contact stimuli) were differentially paired with painful and non-painful heat stimuli. During a test phase, the conditioned response was assessed by pain ratings on delivery of the non-painful heat stimulus (test stimulus) when it was paired with the CS + versus with the CS-. The original analysis classified participants as "responders" or "non-responders", according to a nocebo response framework. Our analysis pooled all the participants' results and compared the percentage of test stimuli rated as painful when paired with the CS + versus with the CS-, and found no significant difference (paired t-test, $\mathrm{t}(20)=1.706$, one-tailed $P=0.052$, 95\% Cl: 0.85-8.47, $r=.36)$. The power level for this analysis was 0.50 .

Williams and Rhudy's study [11] was designed to investigate preparedness theory. They used a differential conditioning procedure with non-somatosensory CSs to condition fear, which was expected to modulate pain threshold. Emotive visual stimuli (pictures of people with facial expressions communicating fear or happiness) were counterbalanced as CS + or CS-. The UCS was an aversive electrocutaneous stimulus. Fear was inferred on the basis of skin conductance response, valence, and arousal, and the effect of conditioned fear on pain threshold was assessed using a test stimulus. The study showed that fear was conditioned, but only when the "fear" facial expression was the CS+. Conditioned fear was associated with a lowered pain threshold, suggesting that allodynia was classically conditioned, albeit indirectly. 


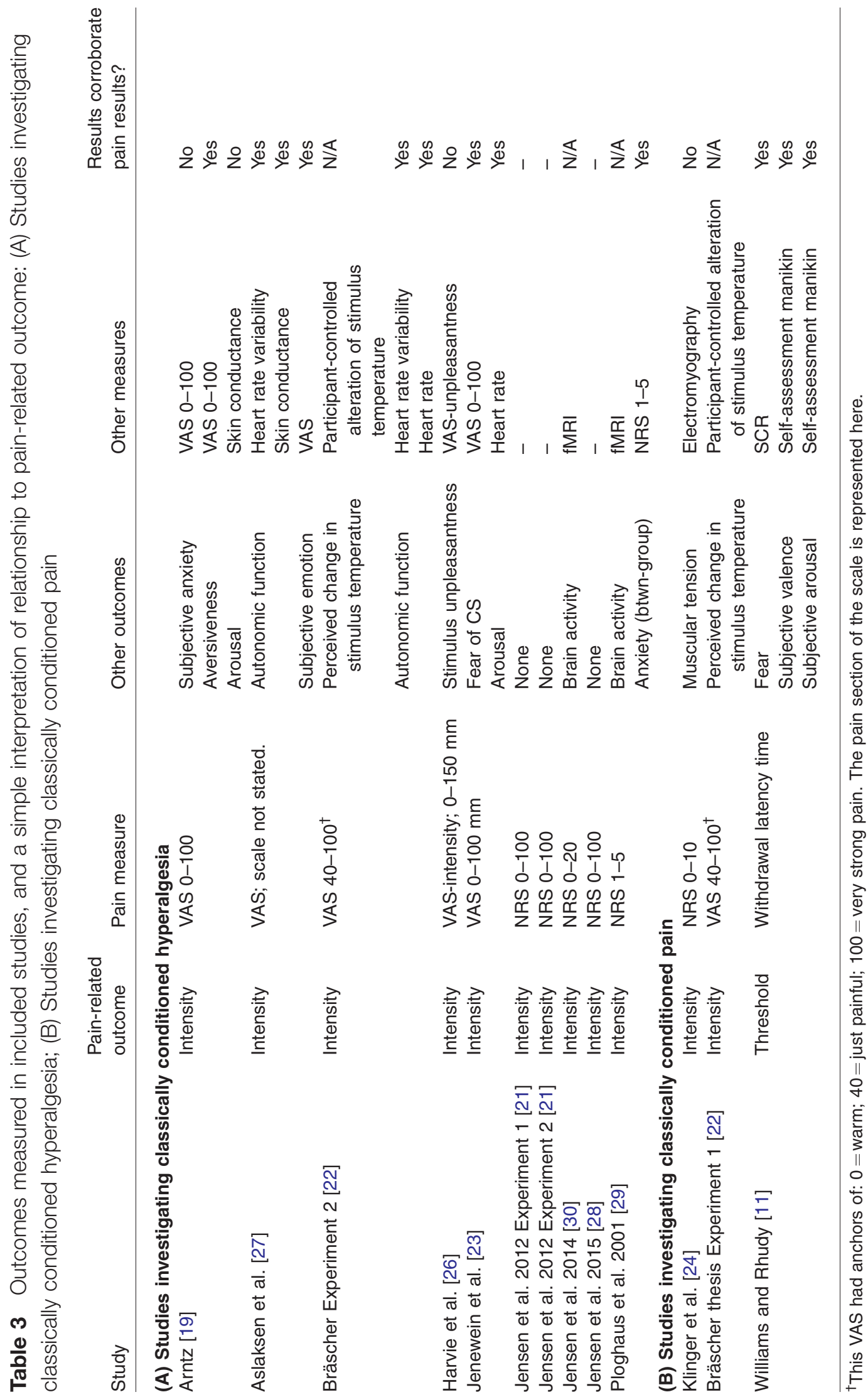




\section{Madden et al.}

Table 4 Results of the risk of bias assessment for included studies: (A) Studies investigating classically conditioned hyperalgesia; (B) Studies investigating classically conditioned pain

\begin{tabular}{|c|c|c|c|c|c|c|}
\hline Study name & $\begin{array}{l}\text { Selection } \\
\text { bias }\end{array}$ & Blinding & $\begin{array}{l}\text { Measurement } \\
\text { bias }\end{array}$ & $\begin{array}{l}\text { Conditioning } \\
\text { procedure }\end{array}$ & $\begin{array}{l}\text { Statistical } \\
\text { methods, } \\
\text { study size, } \\
\text { confoundina }\end{array}$ & $\begin{array}{l}\text { Reporting } \\
\text { bias }\end{array}$ \\
\hline
\end{tabular}

\section{(A) Studies investigating classically conditioned hyperalgesia}

Arntz [19]

Aslaksen et al. [27]

Bräscher thesis Experiment 2 [22]

Harvie et al. [26]

Jenewein et al. [23]

Jensen et al. 2012 Experiment 1 [21]

Jensen et al. 2012 Experiment 2 [21]

Jensen et al. 2014 [30]

Jensen et al. 2015 [28]

Ploghaus et al. 2001 [29]

(B) Studies investic

Bräscher thesis Experiment 1 [22]

Williams and Rhudy [11]
Unclear risk: pilot study mentioned briefly in dissertation

Unclear risk: conference abstract

Low risk High risk Low risk

Unclear risk: article not yet published

Low risk High risk Low risk

Low risk High risk Low risk

Low risk High risk Low risk

High risk High risk Low risk

Unclear risk: article not yet published

High risk High risk Low risk

High risk

High risk

Low risk

Low risk

Low risk

Low risk

High risk Low risk

High risk Low risk

High risk Low risk

Low risk High risk Low risk

conditioned pain

$\begin{array}{llll}\text { High risk } & \text { High risk } & \text { Low risk } & \text { Low risk } \\ \text { Low risk } & \text { High risk } & \text { Low risk } & \text { Low risk } \\ \text { Unclear } & \text { High risk } & \text { High risk* } & \text { Low risk }\end{array}$

Low risk

High risk

Low risk

High risk High risk

High risk Low risk

High risk Low risk

*See note in text regarding measurement bias rating for this study.

The primary question of Klinger et al. [24] concerned classical conditioning of muscular responses in people with chronic tension-type headache, people with chronic back pain, and healthy controls. The CSs were auditory tones, and the UCS was painful: an electrocutaneous stimulus calibrated to twice pain threshold. They collected pain intensity ratings for CS-only trials in all participants, rendering their healthy control group eligible for inclusion in this review. None of the healthy participants rated the CS-only trials (auditory tones) as painful at any stage in the experiment, meaning that allodynia was not classically conditioned in this experiment.

\section{Discussion}

\section{Summary of Results}

This systematic review and meta-analysis aimed to synthesize the evidence that classical conditioning can be used to elicit or amplify pain in healthy, adult humans. Numerous studies have used combined conditioning and verbal suggestion procedures, but we wanted to distinguish the effects of conditioning from verbally cued learning, so we excluded those studies that did not make this distinction $[31,32]$. In summary, our systematic review yielded ten studies that tested for classically conditioned hyperalgesia, of which eight studies demonstrated hyperalgesia and two studies did not. Our review also yielded three studies that allowed for testing of the hypothesis that allodynia can be a classically conditioned response, although only one used pain as the primary outcome. Overall, the results show limited evidence that hyperalgesia can be classically conditioned, and that there are conflicting findings about whether or not allodynia can be classically conditioned. These findings are based on data from 13 studies conducted by nine different research groups, with a cumulative 315 participants (see note on Table 1).

\section{Risk of Bias of Available Literature}

The nine studies in which risk of bias was formally assessed showed varied levels of risk, suggesting that their results should be interpreted with caution. Assessment of blinding was not reported in any study, and all the assessed studies had small sample sizes. This is a feature of the classical conditioning field, and these small samples may be acceptable when powering for large effect sizes. However, the wide confidence intervals seen in the meta-analysis forest plot (Figure 3) suggest that the sample sizes were not sufficiently large to account for the variance in the data. Reporting was generally good, and measurements were chosen well, except in one study by Williams and Rhudy [11]. In that study, pain thresholds were compared using latencies of withdrawal from a test stimulus. Participants' fingers were placed on a radiant heat device and they were instructed to withdraw the finger as soon as the test stimulus became painful. Although this outcome measure was a withdrawal latency time, it functioned as a non-verbal report on the presence of pain (not a measure of a reflexive response) because the instructions required a subjective decision about pain onset. 


\section{Classically Conditioned Pain and Hyperalgesia in Humans}

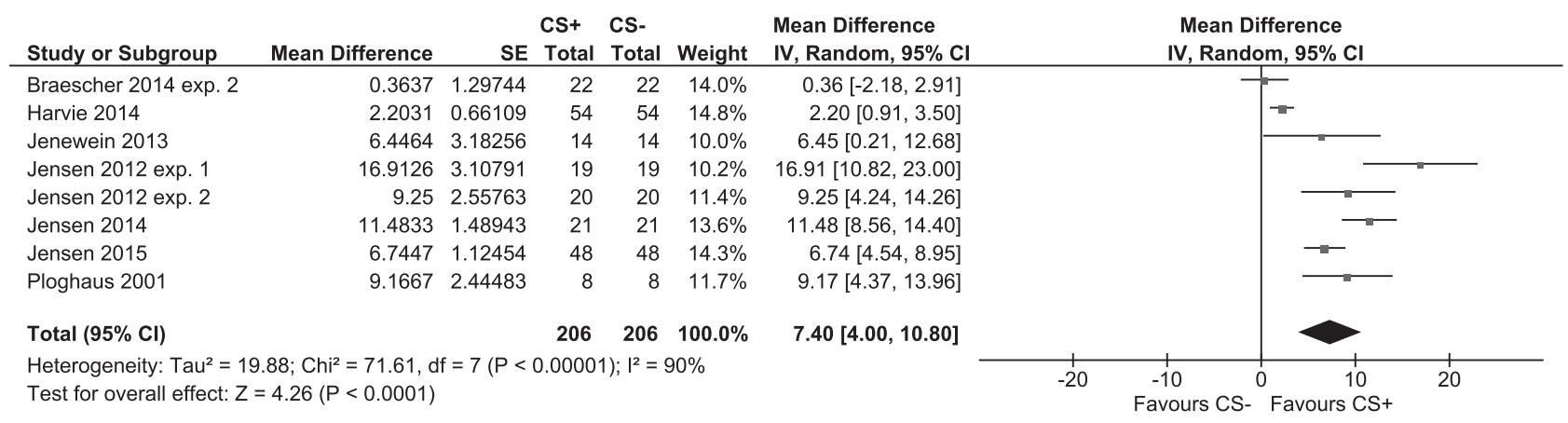

Figure 3 Conditioned response: a forest plot of mean differences in pain intensity. The effect estimate of each study (mean difference) is indicated by a box and its $95 \%$ confidence interval $(\mathrm{Cl})$ is shown with a horizontal line. The pooled effect estimate and its $95 \% \mathrm{Cl}$ is denoted by the diamond. Results are displayed for all eight studies for which full data were available.

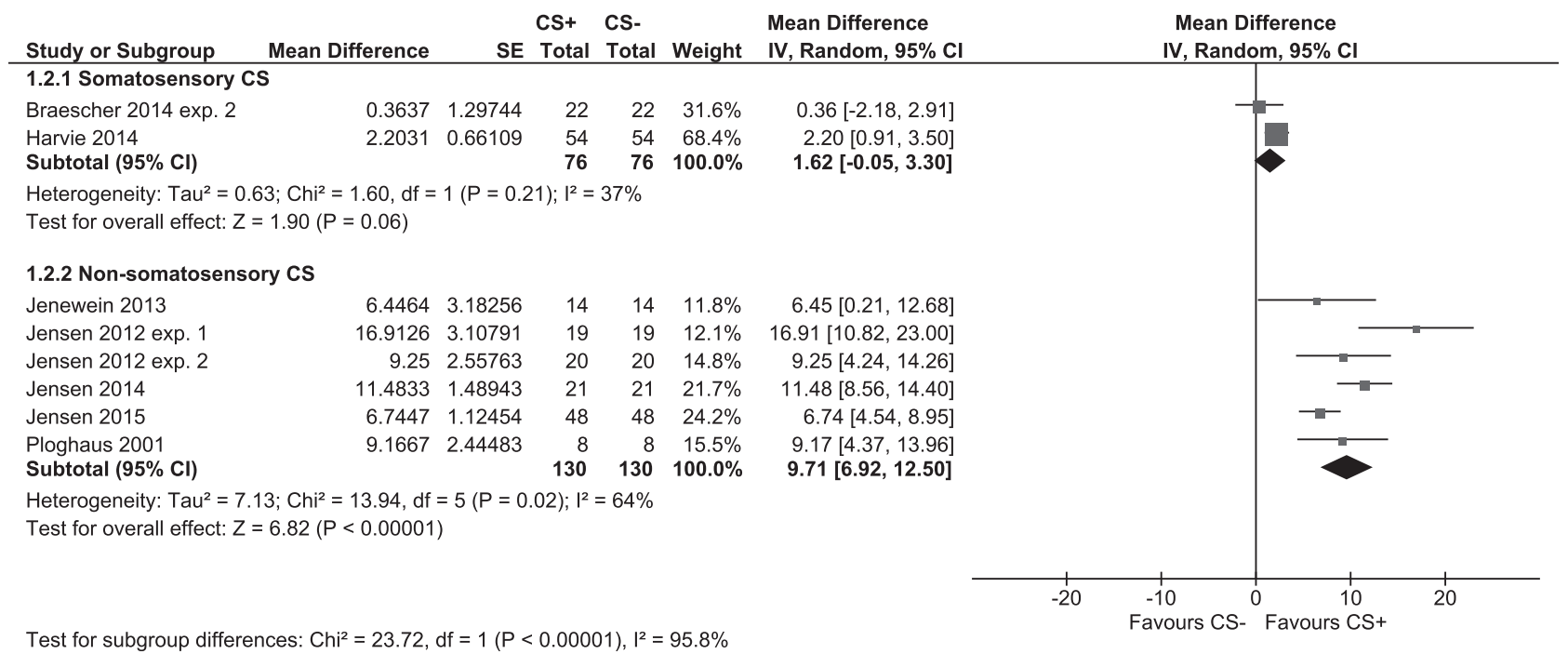

Figure 4 Subgroup analysis of conditioned response: a forest plot of mean differences in pain intensity. The effect estimate of each study (mean difference) is indicated by a box and its $95 \%$ confidence interval $(\mathrm{Cl}$ ) is shown with a horizontal line. The pooled effect estimate and its $95 \% \mathrm{Cl}$ is denoted by the diamond. Results are displayed for studies that used a somatosensory CS and studies that used a non-somatosensory CS.

However, it is also open to contamination by operant conditioning processes, because removal of the finger from the heat device also removed the painful stimulus. Therefore, any change in pain seen in this study could be due to operant as well as classical conditioning processes. Conditioning procedures were also good in all but one case: Bräscher's Experiment 2 [22] scored poorly here because it used a test stimulus that was calibrated to be mildly painful, but was demonstrated to be non-painful on average (mean rating $<40$ on a $0-100$ scale where 40 was anchored with "just painful"). For this reason, the findings of that study should be treated cautiously, because the test stimulus may not have been adequately intense for the study to test the hypothesis it was intended to. The study by Klinger et al. [24] used a conditioning procedure that was not ideally designed to evaluate classical conditioning of allodynia. It scored "low risk of bias" for conditioning procedure for this reason: its design was very conservative for answering the question of this review.

\section{Classical Conditioning of Hyperalgesia}

Eight studies supported the idea that hyperalgesia can be classically conditioned, and two did not support the idea. Two of the five supporting studies that could be assessed for risk of bias had high risk of selection bias, while the only negating study assessed [22 Exp 2] had low risk of selection bias but high risk of bias related to the conditioning procedure itself. The studies from which full data were available showed a range of effect sizes. Pooling of data from all eight studies showed that 


\section{Madden et al.}

laboratory-based classical conditioning procedures can produce an increase in pain that is equivalent to about seven points on a 0-100 self-report scale. Despite the substantial heterogeneity, all six pooled data sets classified as having low risk of bias for the conditioning procedure consistently demonstrated hyperalgesia, providing support for direction of the effect. In fact, the high heterogeneity score likely reflects a genuinely wide variation in study design and experimental procedures. Importantly, that a wide variety of study designs is capable of demonstrating results in a consistent direction strengthens the idea that classically conditioned hyperalgesia is a reproducible phenomenon.

The meta-analysis of hyperalgesia (Figure 2) also highlights that Experiment 1 of Jensen et al. [21] had a notably larger effect size than the other studies (MD $=16.91$, 95\% Cl: 10.82-23.00). One might attribute this to the use of consciously distinguishable CSs in the test phase of that study. However, the most recent study by Jensen et al. [28] contests this idea: using a factorial design to compare groups that received supraliminal CSs, subliminal CSs, or a combination, it showed no difference in effect size between the groups. A second possibility is that the larger effect size in Experiment 1 by Jensen et al. could be due to the high number of CS-UCS pairings: indeed, three of the studies by Jensen et al. $[21,30]$ used more than twice the number of paired CS-UCS presentations during acquisition than most of the other pooled studies. This might be expected to result in a stronger learning effect [33]. However, Ploghaus et al. [29] used only two pairings and found an effect comparable to that seen in Experiment 2 by Jensen et al., suggesting that, while the number of CS-UCS pairings may play a role, it does not entirely explain the variation in effect sizes.

The difference in findings in the subgroups raises the possibility that preferential cues for classical conditioning of hyperalgesia may exist. Specifically, studies that used non-somatosensory CSs showed a greater pooled effect ( $\sim 11$-point increase) than those using somatosensory CSs ( 2-point increase). This finding contradicts the idea that somatosensory cues might be more readily associated with pain than non-somatosensory cues [34], although it could also reflect the small number of studies in each subgroup rather than a true difference.

It is important to note that our meta-analysis did not include data from one study that did not find support for the classical conditioning of hyperalgesia, and one study that did. We were unable to obtain raw data for these studies, and due to lack of available information, they could not be assessed for risk of bias (Table 4). Because the two studies excluded from the meta-analysis drew opposing conclusions, it is unlikely that they would have had a pivotal influence on the estimate of pooled effect size.

Our exploration of the relationship between the relative painfulness of stimuli paired with $\mathrm{CS}+$ and stimuli paired with CS- during the acquisition phase and the test phase highlights the importance of careful calibration of stimuli to individual participants in experimental procedures. This analysis mimicked and extended those carried out by Jensen et al. [21,28], and, with more data, replicated their findings that there is a positive relationship between the difference in pain intensities during acquisition phase and that found in test phase. Although we did not have access to the acquisition phase data from Bräscher, she reported a similar finding: the subgroup of participants in her study who showed a hyperalgesic effect had also reported the stimuli paired with the CS + during the acquisition phase to be more painful than had the subgroup that did not show a hyperalgesic effect [22]. Harvie et al. [26] also reported a greater hyperalgesic effect in those participants whose pain ratings had differed by more than 30 $\mathrm{mm}$ on a 0-150 mm VAS during the acquisition phase. These findings suggest that individual experience, represented by the differences in pain reports for CS + and CS- paired stimuli, influence the hyperalgesia effects. In those cases where participants experienced large differences in CS + and CS- paired stimuli, there may be a stronger "learning signal" that shapes the subsequent pain response.

\section{Theoretical Considerations}

There are theories both to oppose and to support the hypothesis that repeated pairing of a neutral stimulus (or CS) with an aversive stimulus should lead to hyperalgesia to a test stimulus subsequently paired with that CS. The relevance of some of these theories depends on questions of predictability and expectation, and the emotional results thereof. In this review, all nine studies that used a differential design to investigate classically conditioned hyperalgesia-with the exception of a portion from Harvie et al. [26]—used delay or trace stimulus timing, which could, theoretically, allow participants who have learned the association to predict the relative magnitude of the stimulus that follows the CS. The time interval for this possible prediction ranged from $100 \mathrm{~ms}$ $[21,28,30]$ to 15 seconds $[23,29]$. However, four sections of the data come from designs that probably did not allow participants to predict the nature of the stimulus following the CS. In the study by Harvie et al. [26], one third of the participants underwent a procedure that used perceptually simultaneous timing - that is, onset of the UCS coincided with onset of the CS. Exploratory between-group comparisons showed no difference between the hyperalgesic effect in these participants and that in the other participants who underwent trace and delay timing procedures. Similarly, three of the studies by Jensen et al. (2012 Experiment 2, 2014, and 2015) used CSs that were presented too briefly (12 ms) for conscious recognition, and the time interval between onset of CS and onset of UCS was only 100 ms. In fact, the most recent study by Jensen et al. [28] used a between-group comparison to thoroughly interrogate 


\section{Classically Conditioned Pain and Hyperalgesia in Humans}

the influence of conscious recognition of CSs on the conditioned hyperalgesia effect, and found no difference between groups. We contend that this analysis, along with the $100 \mathrm{~ms}$ delay timing, which was probably not enough time for participants to form a clear prediction about what was to come, suggest that an opportunity to predict the intensity of the test stimulus on the basis of conscious recognition of the CS is not critical for conditioned hyperalgesia.

Nevertheless, most of the data in this review came from studies in which prediction was probably possible. Several early theories predict that the impact of an aversive stimulus should be reduced when the stimulus becomes predictable [35,36-38]. According to this principle, painfulness should decrease after pairing. However, there are three problems with relying on this body of work to form hypotheses about classically conditioned modulation of pain. First, this group of theories provides little evidence to suggest that prediction-based modulation of stimulus impact would differ according to the predicted magnitude of the stimulus, because the predictive value of the $\mathrm{CS}+$ might not differ from that of the CS-. In other words, the theories would not clearly predict a different change in reported pain intensity according to whether the rated stimulus followed a danger signal (CS+) or a safety signal (CS-). Second, while most research into these theories confirmed that predictability of the nature of the stimulus led to decreased skin conductance and task interference, changes in reported intensity were less reliable, which suggests that the modulation of subjective experience may be more complex than modulation of physiological outcomes like skin conductance or heart rate [See 35 vs 39]. Third, painfulness was rarely measured in these studies - and when it was, the effects of predictability on reported pain intensity were inconsistent [see 38 for review].

Further support for a hypoalgesic effect could come from the literature on stress and fear. There is already much literature to suggest that fear can be a classically conditioned response after pairing of a neutral CS with a painful UCS $[10,40]$, and the early investigations into the effects of stress and fear on pain suggested that conditioned fear reduced pain $[41,42]$. But subsequent studies have found the reality to be more complex: negative emotions may induce hyperalgesia [43-45] or hypoalgesia $[41,42,45]$ [see 46 for a review]. Some studies have suggested that the relationship between stimuli and the degree to which stimuli pose a threat to the body may be important in determining the consequences of negative emotions on pain $[43,44]$. Others have suggested that the degree of arousal produced by the UCS or stressor is critical: intense arousal may produce an impulse to escape and inhibits pain, whereas mild to moderate arousal may produce a protective state characterized by hypervigilant scanning of the body, which enhances pain $[11,45]$. The perceived risk of bodily injury or the intensity of the aversive stimulus may influence this degree of arousal produced by a procedure
$[45,47]$. Predictability and stress are, therefore, not clear or compelling bases on which to oppose the idea that classical conditioning could lead to hyperalgesia.

In contrast, the consequences of prediction for arousal provide one possible mechanistic explanation for the classically conditioned hyperalgesia seen in most of the studies in this review: it is plausible that the effect was mediated by heightened arousal. Conscious expectation of hyperalgesia has been shown to lead to actual hyperalgesia, a process mediated, at least in part, by the anxiety-linked hormone cholecystokinin [48], and possibly involving the hypothalamo-adrenocortical axis [49]. In fact, two of the fully described studies that confirmed hyperalgesia attributed the increases in pain to fear/anxiety elicited by the conditioned stimulus [23,29]. In a differential conditioning design that uses delay or trace timing, participants would presumably be attending to the conditioning stimuli so as to differentiate between cues predicting threat or safety. If the CS + produces greater arousal than the CS-, and if that arousal is not sufficient to produce an impulse to escape, it should promote an arousal-mediated hyperalgesic effect that is greater to test stimuli paired with the CS + than to test stimuli paired with the CS-. However, it is clear that this mechanism does not explain the data from the studies by Harvie et al. [26] and Jensen et al. [21 Exp 2, 28,30], in which the CS was not a predictive cue. Although psychophysical data from these studies would be required to conclusively rule out a differential effect of fear/anxiety to CS + versus CS-, it is unlikely that these designs allowed sufficient time or sufficient exposure to the CSs to elicit an arousal-mediated effect, yet in both cases, a differential classically conditioned effect of hyperalgesia was found.

A second possible mechanistic explanation is that classically conditioned hyperalgesia is a learned response in its own right, rather than a secondary consequence of predictability, stress, or emotional arousal. Inference-based theories of perception suggest that we form inferences based on an evaluation of sensory and non-sensory information on the background of prior knowledge about the world [3]. A classical conditioning procedure modulates this "knowledge of the world" by establishing the CS as an indicator of the amount and nature of threat to bodily tissues. This proposed mechanism does not require the CS to have a temporally predictive role, but does rely on higher cognitive processing. Three of the experiments by Jensen et al. [21 Exp 2, 28,30] used conditioned cues that were not consciously perceptible and, therefore, could not be explained by this mechanism, so this cannot be the sole process underlying classically conditioned hyperalgesia. As the brain is hierarchically organized, and information may reach the brain at different levels [50], it is likely that pain learning can also take place at lower levels of information processing.

\section{Classical Conditioning of Allodynia}

This systematic review found insufficient evidence to clearly support or refute the idea that classical 


\section{Madden et al.}

conditioning can be used to evoke pain in humans. Only three studies were found to address this question, only one of which assessed for a direct classically conditioned effect and measured pain as the primary outcome.

Bräscher's Experiment 1 [22] was designed to investigate the effects of a classical conditioning procedure on the perception of a thermal stimulus. We applied our own analysis to these data in order to determine whether pairing with a previously learned CS + was sufficient to shift the perception of a non-painful stimulus to painful. This analysis was underpowered $(\beta=0.50)$ and although there was a trend toward the test stimulus being perceived as painful more frequently when paired with the CS + than when paired with the CS-, with a medium effect size, the results failed to reach significance $(P=0.052)$.

The study by Klinger et al. [24] was designed as a between-group study, primarily comparing muscular responses in people with pain to those in healthy controls, and, as such, was not designed to elicit classically conditioned allodynia in healthy people. Eligibility criteria specified a priori in our protocol required us to include this study, but the negative results are unsurprising, considering that, during the test phase, only auditory tones were presented. It seems improbable that an auditory tone would elicit pain in healthy people. In contrast, the study by Williams and Rhudy [11], although investigating preparedness theory, was designed to produce classically conditioned fear, which, the authors reasoned, would lower the pain threshold. Their hypothesis was upheld. In other words, some stimuli that would not have been painful prior to the conditioning procedure would have been painful if experienced after the procedure. We suggest that Williams and Rhudy's study provides evidence that negative affect-mediated allodynia can be classically conditioned, and that the study by Klinger et al. does not negate these findings with equivalent authority, because their experimental design was not ideal for the purpose of evaluating classical conditioning of allodynia. Although Bräscher's Experiment 1 did not show a significant effect, it is not unreasonable to speculate that a more highly powered analysis might have. We therefore submit that allodynia could be a classically conditioned response, but that more studies are required to clarify this issue. This conclusion suggests that, although a lack of supporting evidence for classically conditioned allodynia was exposed over 20 years ago [7], the empirical data are still limited.

It is interesting that so few studies have asked whether classical conditioning can be used to elicit pain, considering the clinical popularity and theoretical plausibility of the idea. Indeed, the literature on classical conditioning of other phenomena related to pain is plentiful $[24,51,52]$. This apparent lack of interest in pain itself may be accounted for by slow uptake of the recognition that pain is an output, rather than an input-an insight that emerged some 30 years ago [12], but that has only recently become accepted. Pain is also a notoriously difficult construct to measure in an experimental setting [53], and the complexity of designing studies to elicit pain in the context of the ethical restraints and implicit safety cues of the laboratory may have deterred other researchers who are interested in this question.

\section{Related Literature}

The studies included in the present review examined the effects of a classical conditioning manipulation without a verbal manipulation of expectancy-a different approach from the many studies of placebo/nocebo effects. Those studies test the efficacy of a sham treatment for reducing or increasing pain under verbally manipulated expectancy, with or without additional conditioning manipulations. A recent important meta-analysis of nocebo effects [54] found that using a sham treatment with a combination of verbally manipulated expectancy and conditioning elicits a greater hyperalgesic effect than verbally manipulated expectancy alone, but it could not quantify the magnitude of nocebo effects when conditioning is used without verbally manipulated expectancy, because no published studies that had used this approach were found. Consequently, our meta-analysis captured data from a pool of studies that is entirely distinct from those included in that meta-analysis of nocebo effects. Interestingly, the placebo literature does contain studies of the utility of classical conditioning for diminishing pain in the absence of verbally manipulated expectancy [e.g. 55,56]. Those studies suggest that classical conditioning can be used to produce hypoalgesia in healthy humans, even without verbal manipulation of expectancy.

\section{Strengths and Limitations}

This systematic and meta-analytical review used a rigorous method to obtain a comprehensive summary of the evidence for whether classical conditioning can be used to elicit or amplify pain in healthy, adult humans. The search strategy used to identify relevant studies was sensitive and comprehensive. Unpublished work was eligible for inclusion, there was no language restriction, and inclusion was not restricted to those studies that evaluated our question as a primary aim, which maximized the chances of identifying research that was relevant to our question. Lastly, that all stages of the review were performed in duplicate by independent reviewers reduces the risk that we may have missed a relevant study. Because we were primarily interested in the idea that classical conditioning could play an etiological role in chronic pain [57], our review intentionally did not investigate diminution of pain, and was limited to studies that used healthy participants. The results should not, therefore, be interpreted as evidence that classical conditioning inevitably increases pain-rather, that it can increase pain, given an appropriate design. Further, our results should not be extrapolated to the effects of procedures that aim to diminish pain, or to people who already have chronic pain. These are separate 


\section{Classically Conditioned Pain and Hyperalgesia in Humans}

questions. The utility of our meta-analytical results was limited by the scarcity of studies directly addressing our primary question. The high risk of bias seen for multiple domains across the included studies is a limitation of the literature base, but clearly carries over to this study. Future studies should address issues of blinding and study size, as well as other possible sources of bias, so as to provide robust findings.

The paucity of studies investigating whether allodynia can be classically conditioned raises questions about a possible publication bias effect. Other researchers may have asked this question and yielded null (and therefore unpublished) results. This is another limitation of the field that clearly carries over to this review. Our sensitive search strategy, which included consultation with several experts in the field, should have minimized the chances of our missing records, but there may yet be studies-particularly older studies that predate electronic databases - that we did not identify.

The validity of this review is enhanced by the exclusion of studies that used explicit verbal suggestion alongside a conditioning procedure. Such combined procedures are common in the literature, but they do not allow for the effects of conditioning to be teased apart from those of verbal suggestion. We can, therefore, be reasonably confident that the effects seen in these studies are due to classical conditioning.

\section{Conclusion and Future Directions}

Our results demonstrate that there is some evidence to support the idea that classical conditioning alone can amplify pain in healthy, adult humans. It is not possible to say with clarity whether or not pain itself can be elicited using classical conditioning. This review exposes a conspicuous gap in the literature. The idea that associative learning underlies the persistence of pain after tissue healing is pervasive in the clinical arena [58, under review]-perhaps reflecting an extension of the knowledge that associative learning underlies fear of pain [52] - but has not been adequately investigated at an experimental level. The finding that pain-related fear is often learned by classical conditioning prompted the development of numerous treatment strategies [59] and led to significant gains in the management of pain-related fear. Similar progress could lie ahead for pain itself. Further rigorous, blinded studies are needed to test whether classical conditioning effects play a role in eliciting pain. If they do, generalization of classically conditioned pain may underlie common clinical observations such as the spreading of pain, or the occurrence of pain in increasingly various situations, as has been proposed in the Imprecision Hypothesis of chronic pain [57]. While this review considered the evidence for classical conditioning of pain in healthy people, a priority for future work will be to review the evidence in people with chronic pain. Such a question fell outside the scope of this review, but constitutes an important step in developing a full understanding of the mechanisms that may underlie persistent pain.

\section{Supplementary Data}

Supplementary Data are available online at http:// www.painmedicine.oxfordjournals.org.

\section{Acknowledgments}

We are grateful to the authors of the included studies for their gracious replies to our emails and, to those who were able to, for supplying their full data sets. We are also very grateful to Neil O'Connell (Brunel University) for his helpful advice on meta-analysis.

\section{References}

1 Moseley GL, Flor H. Targeting cortical representations in the treatment of chronic pain: A review. Neurorehabil Neural Repair 2012;26(6):646-52.

2 Wall PD, Melzack R, Bonica JJ, eds. Textbook of Pain, 3rd edition. New York: Churchill Livingstone; 1994:xvi, 1524.

3 Feldman J. Bayesian models of perceptual organization. In: Johan Wagemans, ed. Handbook of Perceptual Organization. Oxford, UK: Oxford University Press; 2013: 1008-26.

4 Butler DS, Moseley GL. Explain Pain: Revised and Updated, 2nd edition. Adelaide, Australia: Noigroup Publications; 2013.

5 Pavlov IP. Lectures on Conditioned Reflexes. New York: Liverlight Publishing Company; 1928.

6 Goubert L, Crombez G, Peters M. Pain-related fear and avoidance: A conditioning perspective. In: Asmundson GJG, Vlaeyen JWS, Crombez G, eds. Understanding and Treating Fear of Pain. Oxford, UK: University Press; 2004.

7 Crombez G, Baeyens F, Eelen P. Klassieke conditionering en geconditioneerde pijn. Gedragstherapie 1994;27:97-107.

8 Rescorla RA. Pavlovian conditioning: It's not what you think it is. Am Psychol 1988;43(3):151-60.

9 Karos K, Meulders A, Vlaeyen JW. Threatening social context facilitates pain-related fear learning. J Pain 2015;16(3):214-25.

10 Meulders A, Vansteenwegen D, Vlaeyen JW. The acquisition of fear of movement-related pain and associative learning: A novel pain-relevant human fear conditioning paradigm. Pain 2011;152(11):2460-9. 


\section{Madden et al.}

11 Williams AE, Rhudy JL. The influence of conditioned fear on human pain thresholds: Does preparedness play a role? J Pain 2007;8(7):598-606.

12 Wall PD, McMahon SB. The relationship of perceived pain to afferent nerve impulses. Trends Neurosci 1986;9:254-5.

13 Moher D, Liberati A, Tetzlaff J, Altman DG, Group TP. Preferred reporting items for systematic reviews and meta-analyses: The PRISMA statement. PLoS Med 2009;6(7):e1000097

14 Cochrane Handbook for Systematic Reviews of Interventions: The Cochrane Collaboration; 2011. Available at: www.cochrane-handbook.org (accessed 29 July 2013).

15 Nüesch E, Trelle S, Reichenbach S, et al. Small study effects in meta-analyses of osteoarthritis trials: Meta-epidemiological study. BMJ 2010;341:c3515

16 Dechartres A, Trinquart L, Boutron I, Ravaud P. Influence of trial sample size on treatment effect estimates: Meta-epidemiological study. BMJ 2013;346:f2304.

17 Morley S, Eccleston C, Williams A. Systematic review and meta-analysis of randomized controlled trials of cognitive behaviour therapy and behaviour therapy for chronic pain in adults, excluding headache. Pain 1999;80(1-2):1-13.

18 Wunsch A, Philippot P, Plaghki L. Affective associative learning modifies the sensory perception of nociceptive stimuli without participant's awareness. Pain 2003;102(1-2):27-38.

19 Arntz A, Spit S, Merckelbach H. Cued UCS rehearsal and the impact of painful conditioned stimuli: UCS rehearsal increases SCRs but reduces experienced pain. Behav Res Ther 1997;35(7):591-605.

20 Meijboom A. Klassieke Conditionering van Pijn en Analgesia: een onderzoek naar te vraag of pijn klassiek te conditioneren is. [Thesis]. The Rijsuniversiteit Limburg, The Netherlands; 1992.

21 Jensen KB, Kaptchuk TJ, Kirsch I, et al. Nonconscious activation of placebo and nocebo pain responses. Proc Natl Acad Sci U S A 2012;109(39):15959-64.

22 Bräscher A-K. Cognitive and Behavioural Context of Pain Facilitation - Nocebo Conditioning and Uncontrollability-Induced Sensitisation. Mannheim, Germany: Universität Mannheim; 2014.

23 Jenewein J, Moergeli $H$, Sprott $H$, et al. Fear-learning deficits in subjects with fibromyalgia syndrome? Eur J Pain 2013;17(9):1374-84.
24 Klinger R, Matter N, Kothe R, et al. Unconditioned and conditioned muscular responses in patients with chronic back pain and chronic tension-type headaches and in healthy controls. Pain 2010; 150(1):66-74.

25 Arntz A. Pain: Attention, Emotion, Prediction and Control. Rijksuniversiteit Limburg te Maastricht, The Netherlands; 1991.

26 Harvie DS, Meulders A, Madden VJ, et al. When touch predicts pain: Predictive tactile cues enhance perceived intensity of painful stimulation. Manuscript under review. 2015.

27 Aslaksen PM, Flaten MA. Classical conditioning increases autonomic and subjective pain responses in human subjects. Psychophysiology 2006;43:S21-S.

28 Jensen K, Kirsch I, Odmalm S, Kaptchuk TJ, Ingvar M. Classical conditioning of analgesic and hyperalgesic pain responses without conscious awareness. Proceedings of the National Academy of Sciences. 2015;112(25):7863-7.

29 Ploghaus A, Narain C, Beckmann CF, et al. Exacerbation of pain by anxiety is associated with activity in a hippocampal network. J Neurosci 2001; 21(24):9896-903.

30 Jensen KB, Kaptchuk TJ, Chen X, et al. A neural mechanism for nonconscious activation of conditioned placebo and nocebo responses. Cereb Cortex 2014;25(10):3903-10.

31 Benedetti F, Pollo A, Lopiano L, et al. Conscious expectation and unconscious conditioning in analgesic, motor, and hormonal placebo/nocebo responses. J Neurosci 2003;23(10):4315-23.

32 Colloca L, Sigaudo M, Benedetti F. The role of learning in nocebo and placebo effects. Pain 2008; 136(1-2):211-8.

33 Colloca L, Petrovic $\mathrm{P}$, Wager TD, Ingvar $\mathrm{M}$, Benedetti F. How the number of learning trials affects placebo and nocebo responses. Pain 2010; 151(2):430-9.

34 Domjan M. Pavlovian conditioning: A functional perspective. Ann Rev Psychol 2004; 56(1):179-206.

35 Lykken DT, Tellegen A. On the validity of the preception hypothesis. Psychophysiology 1974;11(2):125-32.

36 Katz R. Unconfounded electrodermal measures in assessing the aversiveness of predictable and unpredictable shocks. Psychophysiology 1984;21(4):452-8. 


\section{Classically Conditioned Pain and Hyperalgesia in Humans}

37 Wagner AR. SOP: A model of automatic memory processing in animal behavior. In: Spear N, Miller R, eds. Information Processing in Animals: Memory Mechanisms. New York, USA: Lawrence Erlbaum Associates; 1981:85:5-44.

38 Miller SM. Predictability and human stress: Toward a clarification of evidence and theory. In: Leonard B, ed. Advances in Experimental Social Psychology. Vol. 14. New York, USA: Academic Press; 1981:203-56.

39 Crombez G, Baeyens F, Eelen P. Sensory and temporal information about impending pain: The influence of predictability on pain. Behav Res Ther 1994;32(6):611-22.

40 Meulders A, Vlaeyen JWS. Reduction of fear of movement-related pain and pain-related anxiety: An associative learning approach using a voluntary movement paradigm. Pain 2012;153(7):1504-13.

41 Flor H, Birbaumer N, Schulz R, Grusser SM, Mucha RF. Pavlovian conditioning of opioid and nonopioid pain inhibitory mechanisms in humans. Eur J Pain 2002;6(5):395-402.

42 Flor H., Grusser SM. Conditioned stress-induced analgesia in humans. Eur J Pain 1999;3(4):317-24.

43 Wiertelak EP, Yang HYT, Mooneyheiberger K, Maier SF, Watkins LR. The nature of conditioned anti-analgesia - spinal-cord opiate and anti-opiate neurochemistry. Brain Res 1994;634(2):214-26.

44 Al Absi M, Rokke PD. Can anxiety help us tolerate pain? Pain 1991;46(1):43-51.

45 Rhudy JL, Meagher MW. Fear and anxiety: divergent effects on human pain thresholds. Pain 2000; 84(1):65-75.

46 Wiech K, Tracey I. The influence of negative emotions on pain: Behavioral effects and neural mechanisms. Neurolmage 2009;47(3):987-94.

47 Walters ET. Injury-related behavior and neuronal plasticity: An evolutionary perspective on sensitization, hyperalgesia, and analgesia. In: Ronald JB, Harris RA, eds. International Review of Neurobiology. Vol. 36. San Diego, USA: Academic Press; 1994:325-427.
48 Benedetti F. Placebo and the new physiology of the doctor-patient relationship. Physiological Reviews. 2013;93(3):1207-46.

49 Benedetti F, Amanzio M, Vighetti S, Asteggiano G. The biochemical and neuroendocrine bases of the hyperalgesic nocebo effect. J Neurosci 2006; 26(46):12014-22.

50 Mesulam MM. From sensation to cognition. Brain 1998;121(6):1013-52.

51 Flor $\mathrm{H}$, Birbaumer N, Turk DC. The psychobiology of chronic pain. Adv Behav Res Ther 1990;12(2):47-84.

52 Meulders A, Vlaeyen JW. The acquisition and generalization of cued and contextual pain-related fear: An experimental study using a voluntary movement paradigm. Pain 2013;154(2):272-82.

53 Crombez G. Pijnmodulatie door anticipatie. KU Leuven: University of Leuven; 1994.

54 Petersen GL, Finnerup NB, Colloca L, et al. The magnitude of nocebo effects in pain: A meta-analysis. Pain 2014;155(8):1426-34.

55 Voudouris NJ, Peck CL, Coleman G. The role of conditioning and verbal expectancy in the placebo response. Pain 1990;43(1):121-8.

56 Amanzio M, Benedetti F. Neuropharmacological dissection of placebo analgesia: Expectationactivated opioid systems versus conditioningactivated specific subsystems. J Neurosci 1999; 19(1):484-94.

57 Moseley GL, Vlaeyen JWS. Beyond nociception: The imprecision hypothesis of chronic pain. Pain 2015;156(1):35-8.

58 Madden VJ, Moseley GL. Do clinicians think that pain can be a classically conditioned response to a non-noxious stimulus? Manuscript under review.

59 Bailey KM, Carleton RN, Vlaeyen JWS, Asmundson GJG. Treatments addressing pain-related fear and anxiety in patients with chronic musculoskeletal pain: A preliminary review. Cogn Behav Ther 2009; 39(1):46-63. 